\title{
Statin Use Influence on the Occurrence of Acute Kidney Injury in Patients with Peripheral Arterial Disease
}

\author{
Daisuke Kanai ${ }^{1,2}$, Hideki Fujii ${ }^{1}$, Kentaro Nakai $^{2}$, Keiji Kono ${ }^{1}$, Kentaro Watanabe ${ }^{1}$, Shunsuke Goto ${ }^{1}$ and \\ Shinichi Nishi ${ }^{1}$
}

${ }^{1}$ Division of Nephrology and Kidney Center, Kobe University Graduate School of Medicine, Kobe, Japan

${ }^{2}$ Department of Nephrology and Kidney Center, Kakogawa Central City Hospital, Hyogo, Japan

Aim: Acute kidney injury (AKI) is an important clinical issue in the diagnosis and treatment of cardiovascular diseases. The association between pretreatment by statins and the occurrence of AKI in patients with peripheral arterial diseases $(\mathrm{PAD})$ remains unclear. Therefore, we examined the association between statin therapy and the occurrence of AKI in patients with PAD.

Methods: We retrospectively analyzed data from the endovascular treatment (EVT) database in our hospital. A total of 295 patients who underwent angiography and/or intervention for PAD between October 2011 and March 2016 were enrolled and divided into two groups: those without statins (control group; $\mathrm{N}=157$ ) and those with statins (statin group; $\mathrm{N}=138$ ) for at least 1 month before admission. We examined the occurrence of AKI and its related factors in these patients.

Results: The serum creatinine levels, dose of contrast medium, use of a renin-angiotensin system inhibitor, smoking habit, and blood pressure were similar in both groups. The statin group had more diabetes patients, had patients who were significantly younger, had patients with a higher body mass index (BMI), and had patients with lower low-density lipoprotein cholesterol than the control group. With regard to the occurrence of AKI, there was a significantly lower incidence in the statin group compared with the control group $(5 \%$ vs. $16 \%, p<$ $0.05)$. The result of the multivariate analysis indicated that statin therapy was significantly correlated with lower occurrence rates of AKI $(p<0.05)$.

Conclusions: Our study suggests that statin therapy might prevent the occurrence of AKI after angiography and/or intervention for PAD.

Key words: Statin, Acute kidney injury, Peripheral artery disease

\section{Introduction}

Acute kidney injury (AKI) is associated with increased morbidity and mortality, and patients with severe kidney injury require maintenance hemodialysis. Moreover, even if kidney function is improved, patients with a history of AKI will still have poor outcomes compared with the healthy ones ${ }^{1,2)}$. Therefore, patients with AKI need a large healthcare cost and lengthened hospital stays ${ }^{3)}$. AKI has several risk factors, such as older age, obesity, anemia, chronic kidney disease (CKD), hypertension, diabetes mellitus, heart failure, cardiovascular disease (CVD), surgery, and diuretics. Another important risk factor is the dose of contrast medium ${ }^{4-6}$. Particularly, in patients with $\mathrm{CKD}$, the prevalence of CVD is very high, and they often face situations that require the use of contrast medium ${ }^{7,8)}$. To prevent the occurrence of AKI, several guidelines recommend intravenous hydration with normal saline or sodium bicarbonate before the administration of contrast medium as a standard precaution ${ }^{9-12)}$. However, AKI following

Address for correspondence: Hideki Fujii, Division of Nephrology and Kidney Center, Kobe University Graduate School of Medicine, 7-5-2, Kusunoki-cho, Chuoku, Kobe, Hyogo 650-0017, Japan E-mail: fhideki@med.kobe-u.ac.jp

Received: September 20, 2021 Accepted for publication: December 3, 2021

Copyright@2022 Japan Atherosclerosis Society

This article is distributed under the terms of the latest version of CC BY-NC-SA defined by the Creative Commons Attribution License.

\section{Advance Publication Journal of Atherosclerosis and Thrombosis}




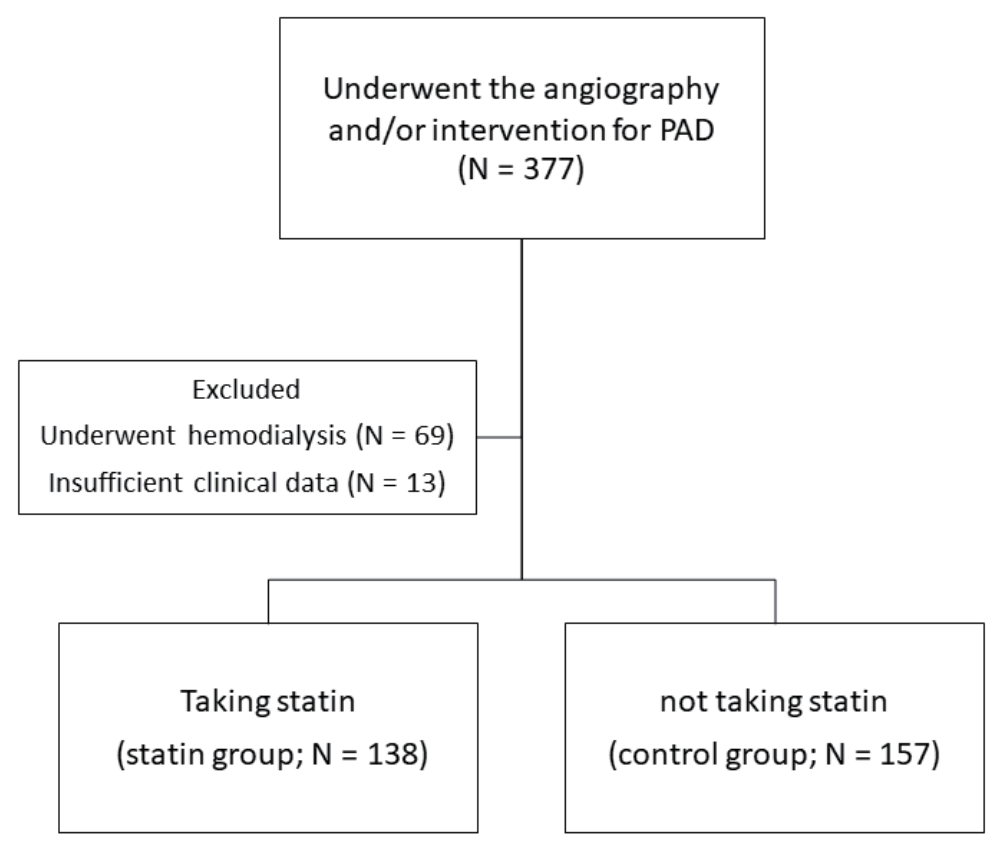

Fig. 1. Enrollment flow diagram for the present study

contrast medium administration cannot be completely prevented. Multiple meta-analysis reported that the onset of AKI in coronary angiography and intervention was significantly suppressed by pretreatment with statins in addition to hydration by isotonic saline ${ }^{13-15)}$.

The presence of peripheral arterial disease (PAD) is closely associated with amputation, other CVD, and mortality. The coexistence of PAD and impaired kidney function has been reported to additively increase mortality rate ${ }^{16,17)}$. Thus, preserving kidney function in patients with PAD seems to be essential. However, there is no specific information on the prevention of AKI with regard to $\mathrm{PAD}$, and the effectiveness of pretreatment with statins for AKI in patients with PAD has not been fully elucidated.

Therefore, we conducted a retrospective study that investigated whether the use of statins was related to the occurrence of AKI in patients with PAD.

\section{Methods}

\section{Study Design and Population}

This was a single-center, retrospective, observational study and was conducted in accordance with the principles stated in the Declaration of Helsinki. Our study protocol was approved by the appropriate institutional review committee (no. 28005).

A total of 377 patients were hospitalized at our institution between October 2011 and March 2016 who underwent angiography and/or intervention for PAD (Fig. 1). PAD was diagnosed by subjective and objective complaints and findings arising from leg ischemia and/or ankle-brachial index <0.9. All the patients underwent ultrasound scan, computed tomography, or magnetic resonance angiography to confirm stenosis of peripheral artery. The severity of $\mathrm{PAD}$ was evaluated using the Rutherford classification. Patients who underwent hemodialysis $(\mathrm{N}=69)$ and those with insufficient clinical data $(\mathrm{N}=13)$ were excluded from the study. Those who took statins for less than 3 months were also excluded. Consequently, 295 patients were included in the analysis. These patients were divided into two groups: those who were taking statins (statin group; $\mathrm{N}=138$ ) and those who were not taking statins (control group; $N=157$ ). All the study patients received a standard hydration therapy before and after angiography and/or intervention for PAD. Isotonic saline $(0.9 \%$ sodium chloride, $1 \mathrm{~mL} / \mathrm{kg} / \mathrm{h}$ ) was administered every $12 \mathrm{~h}$ before and after the procedure. The low-molar, nonionic contrast medium iopamidol (370 mg iodine/ $\mathrm{mL}$, iopamiron ${ }^{\circledR}$ ) was used for all procedures. AKI was defined by the absolute increase in serum creatinine (SCr) of $\geq 0.5 \mathrm{mg} / \mathrm{dL}$ or a relative increase of $\geq 25 \%$ measured within 1 week after performing the procedures according to the KDIGO guideline ${ }^{10)}$.

\section{Statistical Analysis}

Data for continuous variables are expressed as values \pm standard deviation, whereas non-normally distributed variables were expressed as median (quartile). The differences between the groups were

\section{Advance Publication Journal of Atherosclerosis and Thrombosis}


Table 1. Clinical and biochemical characteristics between the statin and control groups

\begin{tabular}{|c|c|c|c|}
\hline & statin group $(\mathrm{N}=138)$ & control group $(\mathrm{N}=157)$ & $P$ \\
\hline Sex (male) & $114(83)$ & $125(80)$ & 0.513 \\
\hline age (year) & $72 \pm 9$ & $76 \pm 9$ & 0.002 \\
\hline BMI $\left(\mathrm{kg} / \mathrm{m}^{2}\right)$ & $22.6 \pm 3.2$ & $21.6 \pm 3.4$ & 0.016 \\
\hline Smoking (\%) & $108(78)$ & $116(74)$ & 0.380 \\
\hline Diabetes mellitus (\%) & $82(59)$ & $74(47)$ & 0.024 \\
\hline Hyperlipidemia (\%) & $138(100)$ & $24(15)$ & $<0.001$ \\
\hline Hypertension (\%) & $92(67)$ & $113(72)$ & 0.323 \\
\hline CKD (\%) & $87(47)$ & $65(55)$ & 0.155 \\
\hline Stage $3(\%)$ & $62(45)$ & $78(50)$ & 0.416 \\
\hline Stage 4-5 (\%) & $3(2)$ & $9(6)$ & 0.113 \\
\hline SBP (mmHg) & $155 \pm 25$ & $158 \pm 35$ & 0.451 \\
\hline DBP (mmHg) & $76 \pm 14$ & $75 \pm 14$ & 0.641 \\
\hline $\mathrm{Cr}(\mathrm{mg} / \mathrm{dL})$ & $0.95 \pm 0.27$ & $0.98 \pm 0.38$ & 0.539 \\
\hline $\mathrm{eGFR}\left(\mathrm{mL} / \mathrm{min} / 1.73 \mathrm{~m}^{2}\right)$ & $59.8 \pm 18.0$ & $60.2 \pm 22.3$ & 0.882 \\
\hline T-cholesterol (mg/dL) & $172 \pm 40$ & $185 \pm 38$ & 0.006 \\
\hline $\mathrm{TG}(\mathrm{mg} / \mathrm{dL})$ & $126 \pm 57$ & $132 \pm 70$ & 0.425 \\
\hline HDL-cholesterol (mg/dL) & $48 \pm 14$ & $48 \pm 14$ & 0.396 \\
\hline LDL-cholesterol (mg/dL) & $100 \pm 32$ & $108 \pm 31$ & 0.017 \\
\hline RAS inhibitor (\%) & $78(57)$ & $76(48)$ & 0.164 \\
\hline Antiplatelet (\%) & $138(100)$ & $157(100)$ & 1.000 \\
\hline Diuretic (\%) & $24(17)$ & $25(16)$ & 0.735 \\
\hline \multicolumn{4}{|l|}{ Rutherford classification } \\
\hline $1(\%)$ & $5(4)$ & $3(2)$ & 0.377 \\
\hline $2(\%)$ & $41(30)$ & $20(13)$ & $<0.001$ \\
\hline $3(\%)$ & $59(43)$ & $73(46)$ & 0.683 \\
\hline $4(\%)$ & $10(7)$ & $14(9)$ & 0.600 \\
\hline $5(\%)$ & $22(15)$ & $42(27)$ & 0.010 \\
\hline $6(\%)$ & $1(1)$ & $5(3)$ & 0.121 \\
\hline
\end{tabular}

BMI: body mass index; CKD: chronic kidney disease; SBP: systolic blood pressure; DBP: diastolic blood pressure; Cr: creatinine; eGFR: estimated glomerular filtration rate; T-cholesterol: total cholesterol; TG: triglyceride; HDL-cholesterol: high density lipoprotein cholesterol; LDL-cholesterol: low density lipoprotein cholesterol; RAS inhibitor: renin-angiotensin-aldosterone system inhibitor.

Table 2. AKI-related parameters between the statin and control groups

\begin{tabular}{lcrc}
\hline & statin group & control group & $P$ \\
\hline AKI $(\%)$ & $7(5.1)$ & $24(15.3)$ & 0.040 \\
Dose of contrast medium $(\mathrm{mL})$ & $62.1 \pm 38.6$ & $59.8 \pm 43.8$ & 0.680 \\
post $\mathrm{Cr}(\mathrm{mg} / \mathrm{dL})$ & $0.99 \pm 0.33$ & $1.04 \pm 0.40$ & 0.539 \\
post eGFR $\left(\mathrm{mL} / \mathrm{min} / 1.73 \mathrm{~m}^{2}\right)$ & $57.8 \pm 18.0$ & $56.1 \pm 21.3$ & 0.424 \\
$\Delta \mathrm{Cr}(\mathrm{mg} / \mathrm{dL})$ & $0.04 \pm 0.16$ & $0.07 \pm 0.17$ & 0.158 \\
$\Delta \mathrm{eGFR}\left(\mathrm{mL} / \mathrm{min} / 1.73 \mathrm{~m}^{2}\right)$ & $-1.85 \pm 8.57$ & $-4.07 \pm 9.49$ & 0.037 \\
\hline
\end{tabular}

AKI: acute kidney injury; Cr: creatinine; eGFR: estimated glomerular filtration rate.

analyzed using Students $t$-test or the Mann-Whitney $U$ test. Categorical variables were expressed as frequencies and percentages, and comparisons were performed using the chi-squared test. Multivariate logistic regression analysis was also performed. For the matching of the clinical characteristics between the two groups, the propensity score was calculated using a logistic regression model from the following factors: sex, age, body mass index (BMI), hypertension, diabetes mellitus, creatinine, use of renin-angiotensin system inhibitors, and dose of contrast medium. Propensity score matching was performed using a

\section{Advance Publication Journal of Atherosclerosis and Thrombosis}


Table 3. Clinical and biochemical characteristics of patients with and without acute kidney injury

\begin{tabular}{|c|c|c|c|}
\hline & AKI group $(n=31)$ & Not AKI group $(n=264)$ & $P$ \\
\hline Sex (male) & $23(74)$ & $216(82)$ & 0.367 \\
\hline age (year) & $78 \pm 9$ & $74 \pm 9$ & 0.008 \\
\hline BMI $\left(\mathrm{kg} / \mathrm{m}^{2}\right)$ & $21 \pm 3.2$ & $22 \pm 3.3$ & 0.070 \\
\hline Smoking (\%) & $24(77)$ & $201(76)$ & 0.838 \\
\hline Diabetes mellitus (\%) & $12(39)$ & $145(55)$ & 0.087 \\
\hline Hyperlipidemia (\%) & $8(27)$ & $135(68)$ & 0.012 \\
\hline Hypertension (\%) & $26(84)$ & $135(68)$ & 0.066 \\
\hline CKD (\%) & $21(68)$ & $132(50)$ & 0.056 \\
\hline Stage $3(\%)$ & $19(61)$ & $121(46)$ & 0.109 \\
\hline Stage 4-5 (\%) & $2(6)$ & $11(4)$ & 0.569 \\
\hline SBP (mmHg) & $149 \pm 26$ & $157 \pm 31$ & 0.108 \\
\hline DBP $(\mathrm{mmHg})$ & $70 \pm 17$ & $76 \pm 13$ & 0.059 \\
\hline $\mathrm{Cr}(\mathrm{mg} / \mathrm{dL})$ & $1.00 \pm 0.41$ & $0.96 \pm 0.32$ & 0.567 \\
\hline $\mathrm{eGFR}\left(\mathrm{mL} / \mathrm{min} / 1.73 \mathrm{~m}^{2}\right)$ & $60.4 \pm 24.5$ & $62.1 \pm 19.6$ & 0.703 \\
\hline T-cholesterol (mg/dL) & $173 \pm 36$ & $179 \pm 40$ & 0.342 \\
\hline $\mathrm{TG}(\mathrm{mg} / \mathrm{dL})$ & $124 \pm 50$ & $130 \pm 65$ & 0.563 \\
\hline HDL-cholesterol (mg/dL) & $45 \pm 14$ & $49 \pm 14$ & 0.190 \\
\hline LDL-cholesterol (mg/dL) & $106 \pm 33$ & $104 \pm 32$ & 0.763 \\
\hline Statin $(\%)$ & $7(23)$ & $132(50)$ & 0.020 \\
\hline RAS inhibitor (\%) & $20(65)$ & $135(51)$ & 0.146 \\
\hline Antiplatelet (\%) & $31(100)$ & $264(100)$ & 1.000 \\
\hline Diuretic (\%) & $9(29)$ & $40(15)$ & 0.115 \\
\hline
\end{tabular}

Acute kidney injury: AKI; BMI: body mass index; CKD: chronic kidney disease; SBP: systolic blood pressure; DBP: diastolic blood pressure; Cr: creatinine; eGFR: estimated glomerular filtration rate; T-cholesterol: total cholesterol; TG: triglyceride; HDL-cholesterol: high density lipoprotein cholesterol; LDL-cholesterol: low density lipoprotein cholesterol; RAS inhibitor: renin-angiotensin-aldosterone system inhibitor.

nearest-neighbor 1:1 matching between the statin and control groups (Supplementary Table 1). P values < 0.05 were considered statistically significant. Statistical analyses were conducted using the JMP software version 9.0.3 (SAS Institute Inc., Cary, NC).

\section{Results}

\section{Patient Characteristics}

Table 1 presents the characteristics and laboratory data of all study patients in the two groups. The percentage of male patients, smoking habit, blood pressure, kidney function, and use of reninangiotensin system inhibitors were similar between the two groups. However, the BMI and percentage of diabetes mellitus were significantly higher, and the total cholesterol and low-density lipoprotein cholesterol levels were significantly lower in the statin group compared with the control group. The statin group also included relatively younger patients. With regard to the kind of stain used, the number of patients taking each statin is as follows: rosuvastatin $(\mathrm{N}=59,42.8 \%)$, atorvastatin $(\mathrm{N}=52,37.7 \%)$, pitavastatin $(\mathrm{N}=11,8.0 \%)$, pravastatin $(\mathrm{N}=11$,
$8.0 \%)$, simvastatin $(\mathrm{N}=3,2.2 \%)$, and fluvastatin $(\mathrm{n}=2,1.4 \%)$.

Data after the Angiography and/or Intervention for PAD

As presented in Table 2, the occurrence of AKI was significantly lower in the statin group compared with the control group $(5.1 \%$ vs. $15.3 \%$, respectively, $p<0.05)$. The dose of contrast medium administered was similar between the two groups. The changes in the estimated glomerular filtration rate (eGFR) were significantly greater in the control group than in the statin group.

Correlation between the Occurrence of AKI and Clinical Factors

Univariate analysis revealed that the occurrence of AKI was significantly correlated with age $(\mathrm{r}=0.149$, $p<0.05)$, BMI $(\mathrm{r}=-0.118, p<0.05)$, hyperlipidemia $(\mathrm{r}=-0.147, p<0.05)$, diastolic blood pressure $(\mathrm{r}=-0.147, p<0.05)$, and statin use $(\mathrm{r}=-0.166, p<$ $0.05)$ in all the study patients. Interestingly, as presented in Table 3, the eGFR before the angiography and/or intervention was comparable between the AKI

\section{Advance Publication Journal of Atherosclerosis and Thrombosis}


Table 4. Association between acute kidney injury and clinical factors

\begin{tabular}{lccc}
\hline & OR & $95 \%$ CI & $P$ \\
\hline Statin & 0.342 & $0.139-0.839$ & 0.019 \\
Age & 1.050 & $1.002-1.101$ & 0.039 \\
BMI & 0.961 & $0.855-1.080$ & 0.505 \\
DBP & 0.970 & $0.942-0.999$ & 0.044 \\
\hline
\end{tabular}

OR; odds ratio, CI; confidential interval, BMI; body mass index, DBP; diastolic blood pressure

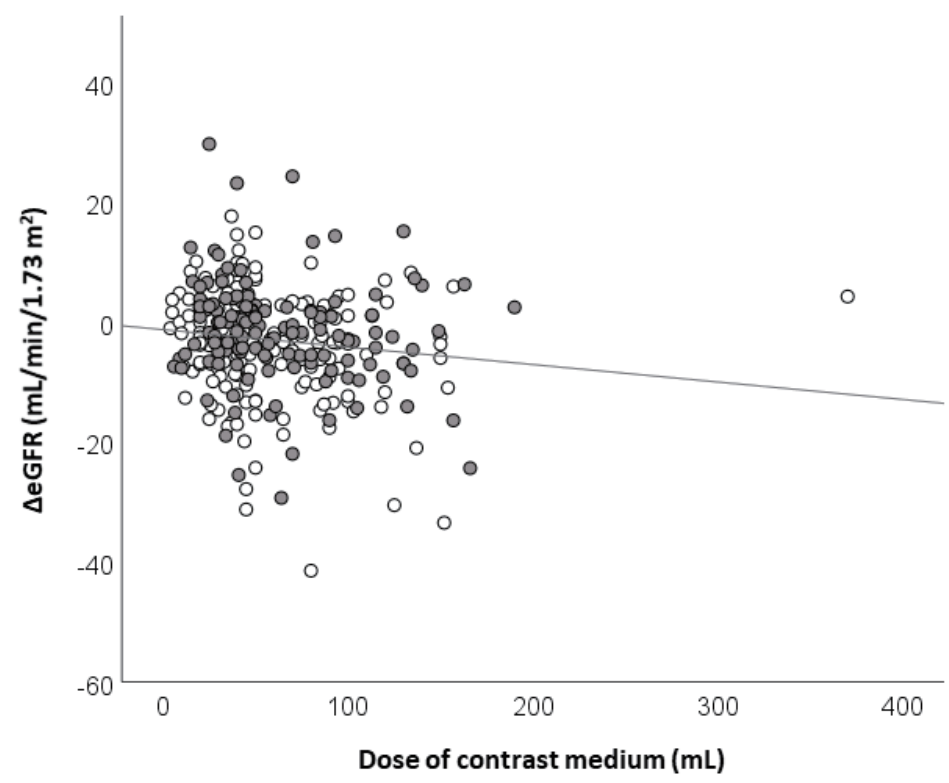

Fig. 2. Correlation between the dose of contrast medium and eGFR

eGFR, estimated glomerular filtration rate

White circle, control group; gray circle, statin group

and non-AKI groups, and it was not significantly associated with the occurrence of AKI. Multivariate analysis, including age, BMI, diastolic blood pressure, and statin use, revealed that the occurrence of AKI was significantly and negatively associated with the use of statin (Table 4). A similar result was observed in patients with diabetes or who were older than 70 years. Furthermore, we conducted multivariate analysis after the propensity score matching. The result also indicated that statin therapy had a significantly positive influence on AKI (odds ratio 0.367; 95\% CI 0.144-0.934; $p<0.05$ ).

\section{Correlation between Changes in Kidney Function} and the Dose of Contrast Medium

Although the dose of contrast medium was comparable between the two groups, we evaluated the relationship between the dose of contrast medium and the changes in kidney function. In all the study patients, as presented in Fig. 2, the dose of contrast medium was significantly correlated with the changes in the eGFR $(r=-0.163, p<0.05)$. This significant correlation was preserved if analyzed in each group independently.

\section{Discussion}

The present study demonstrated that (1) the use of statin was significantly associated with lower prevalence of AKI following angiography and/or intervention for PAD, and (2) the dose of contrast medium was significantly correlated with the changes in the eGFR.

PAD is an important complication as its progression is related to critical problems, such as claudication, rest pain, ischemic ulcers, amputation, and hospitalization ${ }^{11)}$. Since most patients with PAD have diabetes and dyslipidemia, they are at a high risk for atherosclerotic CVD progression ${ }^{18)}$. In fact, it has been reported that patients with PAD have a higher 
risk for myocardial infarction, stroke, and mortality compared with those without PAD ${ }^{19-21)}$. Our study participants also frequently had complications associated with CVD, such as coronary artery disease, stroke, and aortic disease. Furthermore, although kidney function is also an important risk factor for CVD, this study included 152 patients with CKD at baseline $(51.5 \%)$. Therefore, preventing the further progression of kidney dysfunction seems to be very important to improve the patients quality of life and prognosis.

Although several etiologies of AKI following angiography and/or intervention in patients with PAD have been proposed, its pathophysiological mechanisms are very complex. The dose of contrast media, cholesterol embolization, infection, and anemia due to bleeding has been suggested to contribute to the occurrence of AKI following angiography and/or intervention ${ }^{22-26)}$. Among them, the dose of contrast media is the most crucial risk factor in clinical settings. The mechanisms of AKI due to the dose of contrast media involve endothelial cell injury, tubular epithelial cell injury, and impaired kidney microcirculation by exerting direct toxic effects and altering the kidney hemodynamics ${ }^{27-29)}$. The dose of contrast media is reported to enhance the formation of reactive oxygen species and thereby reduce microcirculation by decreasing nitric oxide production $^{30)}$. Furthermore, many studies reported that the dose of contrast media is associated with the occurrence of $\mathrm{AKI}{ }^{31,32)}$. Therefore, contrast media reduction is recommended by current guidelines ${ }^{10-12)}$. Our data also indicated that the dose of contrast media was significantly associated with changes in the eGFR. Furthermore, this significant correlation was observed in both the control and statin groups.

Statins are commonly used medicine and prescribed extensively for lowering cholesterol levels to prevent CVD. Several recent studies showed that statins did not only have lipid-lowering effects but also pleiotropic effects ${ }^{33-35)}$. Several randomized controlled trials demonstrated the effectiveness of statins in the prevention of AKI after contrast mediainduced nephropathy in patients undergoing coronary angiography ${ }^{36-38)}$. The occurrence rates of AKI in patients with and without statins were $3.7 \%$ and $8.3 \%$, respectively. Nevertheless, there were no reports on the prevention of AKI following angiography and/ or intervention using statins in patients with PAD. Thus, we investigated the possible effectiveness of statins on the occurrence of AKI in these patients. The result of our study indicated that the occurrence rates of AKI in patients with and without statins were 5.0\% and $15.0 \%$, respectively. The number of patients with
AKI who were undergoing coronary angiography was greater in the present study than in the previous studies. A previous systematic review that included 11,311 patients with PAD has reported that the median incidence of AKI in the studies was $10 \%{ }^{39)}$. This result corresponded with our study results. We speculated that the difference in the AKI rate was caused by the other underlying diseases experienced by these patients, because patients with PAD might have more severe atherosclerotic lesions ${ }^{18)}$. In addition, the dose of statins was lower in this study than in other previous studies, given that the dose admitted by health insurance providers in Japan is different from that in other countries. Therefore, this finding would be valuable because the findings from our study suggested that a low-dose statin therapy might prevent the occurrence of AKI even in patients with PAD who are undergoing angiography and/or intervention.

This study had several limitations. The number of enrolled patients was relatively small. Therefore, there was a possibility that we could not perform statistically sufficient adjustments. In addition, longterm evaluation was not conducted in this study. A long-term study is needed to ascertain the influence of statins on kidney function.

\section{Conclusions}

Our data suggests that the use of statins might reduce the occurrence of AKI after angiography and/ or intervention for PAD. However, a further detailed study is needed to prove the reno-protective effects of statins.

\section{Acknowledgements}

This study was presented in part at the American Society of Nephrology, 2018 in New Orleans, U.S.A.

\section{Funding}

None.

\section{Conflict of Interest}

H.F. received lecture fees from AstraZeneca PLC.

\section{References}

1) Heung M, Chawla LS. Acute kidney injury: gateway to chronic kidney disease. Nephron Clin Pract, 2014; 127: 30-34

2) Chawla LS, Eggers PW, Star RA, Kimmel PL. Acute kidney injury and chronic kidney disease as 
interconnected syndromes. N Engl J Med, 2014; 371: 58-66

3) McCullough PA, Wolyn R, Rocher LL, Levin RN, O'Neill WW. Acute renal failure after coronary intervention: incidence, risk factors, and relationship to mortality. Am J Med, 1997; 103: 368-375

4) Lameire N, Adam A, Becker CR, Davidson C, McCullough PA, Stacul F, Tumlin J, CIN Consensus Working Panel. Baseline renal function screening. Am J Cardiol, 2006; 98: 21K-26K

5) La Manna G, Pancaldi LG, Capecchi A, Maska E, Comai G, Cappuccilli ML, Carretta E, Lombardi A, Coli L, Stefoni S. Risk for contrast nephropathy in patients undergoing coronarography. Artif Organs, 2010; 34: E193-199

6) Solomon R, Werner C, Mann D, D'Elia J, Silva P. Effects of saline, mannitol, and furosemide on acute decreases in renal function induced by radiocontrast agents. $\mathrm{N}$ Engl J Med, 1994; 331: 1416-1420

7) Nakayama M, Metoki H, Terawaki H, Ohkubo T, Kikuya $M$, Sato $T$, Nakayama $K$, Asayama $K$, Inoue $R$, Hashimoto J, Totune K, Hoshi H, Ito S, Imai Y. Kidney dysfunction as a risk factor for first symptomatic stroke events in a general Japanese population--the Ohasama study. Nephrol Dial Transplant, 2007; 22: 1910-1915

8) Manjunath G, Tighiouart H, Ibrahim H, MacLeod B, Salem DN, Griffith JL, Coresh J, Levey AS, Sarnak MJ. Level of kidney function as a risk factor for atherosclerotic cardiovascular outcomes in the community. J Am Coll Cardiol, 2003; 41: 47-55

9) Jurado-Román A, Hernández-Hernández F, García-Tejada J, Granda-Nistal C, Molina J, Velázquez M, Albarrán A, Tascón J. Role of hydration in contrast-induced nephropathy in patients who underwent primary percutaneous coronary intervention. Am J Cardiol, 2015; 115: 1174-1178

10) Khwaja A. KDIGO clinical practice guidelines for acute kidney injury. Nephron Clin Pract, 2012; 120: c179-184

11) Hirsch AT, Haskal ZJ, Hertzer NR, Bakal CW, Creager MA, Halperin JL, Hiratzka LF, Murphy WR, Olin JW, Puschett JB, Rosenfield KA, Sacks D, Stanley JC, Taylor LM Jr, White CJ, White J, White RA, Antman EM, Smith SC Jr, Adams CD, Anderson JL, Faxon DP, Fuster V, Gibbons RJ, Hunt SA, Jacobs AK, Nishimura R, Ornato JP, Page RL, Riegel B; American Association for Vascular Surgery; Society for Vascular Surgery; Society for Cardiovascular Angiography and Interventions; Society for Vascular Medicine and Biology; Society of Interventional Radiology; ACC/AHA Task Force on Practice Guidelines Writing Committee to Develop Guidelines for the Management of Patients With Peripheral Arterial Disease; American Association of Cardiovascular and Pulmonary Rehabilitation; National Heart, Lung, and Blood Institute; Society for Vascular Nursing; TransAtlantic Inter-Society Consensus; Vascular Disease Foundation. ACC/AHA 2005 Practice Guidelines for the management of patients with peripheral arterial disease (lower extremity, renal, mesenteric, and abdominal aortic): a collaborative report from the American Association for Vascular Surgery/Society for Vascular Surgery, Society for Cardiovascular Angiography and
Interventions, Society for Vascular Medicine and Biology, Society of Interventional Radiology, and the ACC/AHA Task Force on Practice Guidelines (Writing Committee to Develop Guidelines for the Management of Patients with Peripheral Arterial Disease): endorsed by the American Association of Cardiovascular and Pulmonary Rehabilitation; National Heart, Lung, and Blood Institute; Society for Vascular Nursing; TransAtlantic Inter-Society Consensus; and Vascular Disease Foundation. Circulation, 2006; 113: e463-654

12) Kodzwa R. Acr manual on contrast media: 2018 updates. Radiol Technol, 2019; 91: 97-100

13) Singh N, Lee JZ, Huang JJ, Low SW, Howe C, Pandit A, Suryanarayana P, Lee KS. Benefit of statin pretreatment in prevention of contrast-induced nephropathy in different adult patient population: systematic review and metaanalysis. Open Heart, 2014; 1: e000127

14) Sun Y-Y, Liu L-Y, Sun T, Wu M-Y, Ma F-Z. Prophylactic atorvastatin prior to intra-arterial administration of iodinated contrast media for prevention of contrastinduced acute kidney injury: A meta-analysis of randomized trial data. Clin Nephrol, 2019; 92: 123-130

15) Wang N, Qian P, Yan TD, Phan K. Periprocedural effects of statins on the incidence of contrast-induced acute kidney injury: A systematic review and trial sequential analysis. Int J Cardiol, 2016; 206: 143-152

16) Liew YP, Bartholomew JR, Demirjian S, Michaels J, Schreiber MJ. Combined effect of chronic kidney disease and peripheral arterial disease on all-cause mortality in a high-risk population. Clin J Am Soc Nephrol, 2008; 3: 1084-1089

17) Adam DJ, Bradbury AW. TASC II document on the management of peripheral arterial disease. Eur J Vasc Endovasc Surg, 2007; 33: 1-2

18) Kang Y-P, Chen L-Y, Kang T-D, Liu W-X. Clinical characteristics and adverse events in acute coronary syndrome patients with a history of peripheral arterial disease. Arq Bras Cardiol, 2019; 113: 367-372

19) Resnick HE, Lindsay RS, McDermott MM, Devereux RB, Jones KL, Fabsitz RR, Howard BV. Relationship of high and low ankle brachial index to all-cause and cardiovascular disease mortality: the Strong Heart Study. Circulation, 2004; 109: 733-739

20) Ankle Brachial Index Collaboration; Fowkes FGR, Murray GD, Butcher I, Heald CL, Lee RJ, Chambless LE, Folsom AR, Hirsch AT, Dramaix M, deBacker G, Wautrecht JC, Kornitzer M, Newman AB, Cushman M, Sutton-Tyrrell K, Fowkes FGR, Lee AJ, Price JF, d'Agostino RB, Murabito JM, Norman PE, Jamrozik K, Curb JD, Masaki KH, Rodríguez BL, Dekker JM, Bouter LM, Heine RJ, Nijpels G, Stehouwer CDA, Ferrucci L, McDermott MM, Stoffers HE, Hooi JD, Knottnerus JA, Ogren M, Hedblad B, Witteman JC, Breteler MMB, Hunink MGM, Hofman A, Criqui MH, Langer RD, Fronek A, Hiatt WR, HammanR, Resnick HE, Guralnik J, McDermott MM. Ankle brachial index combined with Framingham Risk Score to predict cardiovascular events and mortality: a meta-analysis. JAMA, 2008; 300: 197208

21) Criqui $\mathrm{MH}$, Langer RD, Fronek $A$, Feigelson HS, Klauber MR, McCann TJ, Browner D. Mortality over a 
period of 10 years in patients with peripheral arterial disease. N Engl J Med, 1992; 326: 381-386

22) Brar SS, Aharonian V, Mansukhani P, Moore N, Shen AYJ, Jorgensen M, Dua A, Short L, Kane K. Haemodynamic-guided fluid administration for the prevention of contrast-induced acute kidney injury: the POSEIDON randomised controlled trial. Lancet, 2014; 383: $1814-1823$

23) Fukumoto $Y$, Tsutsui $H$, Tsuchihashi $M$, Masumoto A, Takeshita A, Cholesterol Embolism Study (CHEST) Investigators. The incidence and risk factors of cholesterol embolization syndrome, a complication of cardiac catheterization: a prospective study. J Am Coll Cardiol, 2003; 42: 211-216

24) Shacham Y, Leshem-Rubinow E, Gal-Oz A, Arbel Y, Keren G, Roth A, Steinvil A. Acute cardio-renal syndrome as a cause for renal deterioration among myocardial infarction patients treated with primary percutaneous intervention. Can J Cardiol, 2015; 31: 1240-1244

25) Narula A, Mehran R, Weisz G, Dangas GD, Yu J, Généreux P, Nikolsky E, Brener SJ, Witzenbichler B, Guagliumi G, Clark AE, Fahy M, Xu K, Brodie BR, Stone GW. Contrast-induced acute kidney injury after primary percutaneous coronary intervention: results from the HORIZONS-AMI substudy. Eur Heart J, 2014; 35: 1533-1540

26) Ohno $Y$, Maekawa $Y$, Miyata $H$, Inoue $S$, Ishikawa $S$, Sueyoshi K, Noma S, Kawamura A, Kohsaka S, Fukuda K. Impact of periprocedural bleeding on incidence of contrast-induced acute kidney injury in patients treated with percutaneous coronary intervention. J Am Coll Cardiol, 2013; 62: 1260-1266

27) Sendeski M, Patzak A, Pallone TL, Cao C, Persson AE, Persson PB. Iodixanol, constriction of medullary descending vasa recta, and risk for contrast mediuminduced nephropathy. Radiology, 2009; 251: 697-704

28) Liu ZZ, Schmerbach K, Lu Y, Perlewitz A, Nikitina T, Cantow K, Seeliger E, Persson PB, Patzak A, Liu R, Sendeski MM. Iodinated contrast media cause direct tubular cell damage, leading to oxidative stress, low nitric oxide, and impairment of tubuloglomerular feedback. Am J Physiol Renal Physiol, 2014; 306: F864-872

29) Ribeiro L, de Assunção e Silva F, Kurihara RS, Schor N, Mieko E, Higa S. Evaluation of the nitric oxide production in rat renal artery smooth muscle cells culture exposed to radiocontrast agents. Kidney Int, 2004; 65: 589-596

30) Pisani A, Riccio E, Andreucci M, Faga T, Ashour M, Nuzzi AD, Mancini A, Sabbatini M. Role of reactive oxygen species in pathogenesis of radiocontrast-induced nephropathy. Biomed Res Int, 2013; 2013: 868321
31) Nyman U, Björk J, Aspelin P, Marenzi G. Contrast medium dose-to-GFR ratio: a measure of systemic exposure to predict contrast-induced nephropathy after percutaneous coronary intervention. Acta Radiol, 2008; 49: 658-667

32) Brown JR, Robb JF, Block CA, Schoolwerth AC, Kaplan AV, O'Connor GT, Solomon RJ, Malenka DJ. Does safe dosing of iodinated contrast prevent contrast-induced acute kidney injury? Circ Cardiovasc Interv, 2010; 3: 346-350

33) Upadhyay A, Earley A, Lamont JL, Haynes S, Wanner C, Balk EM. Lipid-lowering therapy in persons with chronic kidney disease: a systematic review and meta-analysis. Ann Intern Med, 2012; 157: 251-262

34) Athyros VG, Mikhailidis DP, Liberopoulos EN, Kakafika AI, Karagiannis A, Papageorgiou AA, Tziomalos K, Ganotakis ES, Elisaf M. Effect of statin treatment on renal function and serum uric acid levels and their relation to vascular events in patients with coronary heart disease and metabolic syndrome: a subgroup analysis of the GREek Atorvastatin and Coronary heart disease Evaluation (Greace) Study. Nephrol Dial Transplant, 2007; 22: 118-127

35) Scolari F, Ravani P, Gaggi R, Santostefano M, Rollino C, Stabellini N, Colla L, Viola BF, Maiorca P, Venturelli C, Bonardelli S, Faggiano P, Barrett BJ. The challenge of diagnosing atheroembolic renal disease: clinical features and prognostic factors. Circulation, 2007; 116: 298-304

36) Cho Aj, Lee Y-K, Sohn SY. Beneficial effect of statin on preventing contrast-induced acute kidney injury in patients with renal insufficiency: A meta-analysis. Medicine (Baltimore), 2020; 99: e19473

37) Li H, Wang C, Liu C, Li R, Zou M, Cheng G. Efficacy of short-term statin treatment for the prevention of contrastinduced acute kidney injury in patients undergoing coronary angiography/percutaneous coronary intervention: a meta-analysis of 21 randomized controlled trials. Am J Cardiovasc Drugs, 2016; 16: 201-219

38) Giacoppo D, Gargiulo G, Buccheri S, Aruta P, Byrne RA, Cassese S, Dangas G, Kastrati A, Mehran R, Tamburino C, Capodanno D. Preventive strategies for contrastinduced acute kidney injury in patients undergoing percutaneous coronary procedures: evidence from a hierarchical bayesian network meta-analysis of 124 trials and 28240 patients. Circ Cardiovasc Interv, 2017; 10: e004383

39) Prasad A, Ortiz-Lopez C, Khan A, Levin D, Kaye DM. Acute kidney injury following peripheral angiography and endovascular therapy: A systematic review of the literature. Catheter Cardiovasc Interv, 2016; 88: 264-273 
Supplementary Table 1. Comparison of clinical characteristics between the statin and control groups of propensity score matching

\begin{tabular}{|c|c|c|c|}
\hline & statin group $(n=113)$ & control group $(n=113)$ & $P$ \\
\hline Sex (male) & $93(82)$ & $92(81)$ & 0.734 \\
\hline age (year) & $74 \pm 8$ & $74 \pm 9$ & 0.814 \\
\hline BMI $\left(\mathrm{kg} / \mathrm{m}^{2}\right)$ & $22.3 \pm 3.1$ & $22.2 \pm 3.5$ & 0.861 \\
\hline Smoking (\%) & $86(76)$ & $86(76)$ & 1.000 \\
\hline Diabetes mellitus (\%) & $68(60)$ & $66(58)$ & 0.788 \\
\hline Hyperlipidemia (\%) & $98(87)$ & $19(17)$ & $<0.001$ \\
\hline Hypertension (\%) & $80(71)$ & $80(71)$ & 1.000 \\
\hline CKD (\%) & $60(53)$ & $58(51)$ & 0.791 \\
\hline SBP $(\mathrm{mmHg})$ & $157 \pm 25$ & $153 \pm 23$ & 0.206 \\
\hline DBP (mmHg) & $76 \pm 13$ & $75 \pm 13$ & 0.693 \\
\hline $\mathrm{Cr}(\mathrm{mg} / \mathrm{dL})$ & $0.98 \pm 0.28$ & $0.94 \pm 0.33$ & 0.436 \\
\hline eGFR $\left(\mathrm{mL} / \mathrm{min} / 1.73 \mathrm{~m}^{2}\right)$ & $60.0 \pm 18.5$ & $64.0 \pm 22.7$ & 0.144 \\
\hline T-cholesterol (mg/dL) & $172 \pm 41$ & $186 \pm 39$ & 0.009 \\
\hline $\mathrm{TG}(\mathrm{mg} / \mathrm{dL})$ & $125 \pm 59$ & $133 \pm 64$ & 0.306 \\
\hline HDL-cholesterol (mg/dL) & $49 \pm 14$ & $49 \pm 15$ & 0.974 \\
\hline LDL-cholesterol (mg/dL) & $100 \pm 33$ & $109 \pm 32$ & 0.039 \\
\hline RAS inhibitor (\%) & $64(57)$ & $61(54)$ & 0.690 \\
\hline Antiplatelet (\%) & $113(100)$ & $113(100)$ & 1.000 \\
\hline Diuretic $(\%)$ & $20(18)$ & $18(16)$ & 0.723 \\
\hline Dose of contrast medium (mL) & $60 \pm 39$ & $61 \pm 45$ & 0.724 \\
\hline
\end{tabular}

BMI: body mass index; CKD: chronic kidney disease; SBP: systolic blood pressure; DBP: diastolic blood pressure; Cr: creatinine; eGFR: estimated glomerular filtration rate; T-cholesterol: total cholesterol; TG: triglyceride; HDL-cholesterol: high density lipoprotein cholesterol; LDL-cholesterol: low density lipoprotein cholesterol; RAS inhibitor: renin-angiotensin-aldosterone system inhibitor. 